\title{
On the generality of conditioned bradycardia in rabbits: Assessment of CS and US modality
}

\author{
D. A. POWELL \\ Wm. Jennings Bryan Dorn VA Medical Center, Columbia, South Carolina \\ University of South Carolina, Columbia, South Carolina \\ and University of Souih Carolina School of Medicine, Columbia, South Carolina \\ CHARLES M. GIBBS and BRIAN MAXWELL \\ Wm. Jennings Bryan Dorn VA Medical Center, Columbia, South Carolina \\ and University of South Carolina, Columbia, South Carolina \\ and \\ DIANNE LEVINE-BRYCE \\ Wm. Jennings Bryan Dorn VA Medical Center, Columbia, South Carolina
}

\begin{abstract}
To determine whether the magnitude of heart rate (HR) slowing induced by classical conditioning contingencies is comparable under a broad range of stimulus conditions, experiments were conducted in which rabbits were exposed to tones, increases in illumination, or vibratory stimuli as conditioned stimuli (CSs) and in which paraorbital electric shocks, corneal airpuffs, or intraoral pulses of water served as unconditioned stimuli (USs). The results indicated that conditioned bradycardia was elicited by all three CSs. Moreover, when a corneal airpuff served as the US, small but reliable CS-evoked HR decelerations also occurred. Finally, CS-evoked HR slowing also occurred in response to a tone CS employed in an appetitive task, in which water was the US. These findings suggest that HR slowing is a general phenomenon that occurs when rabbits are exposed to signals that systematically predict aversive or appetitive consequences according to a Pavlovian conditioning paradigm.
\end{abstract}

It is well established that a variety of learned autonomic changes are induced by classical conditioning contingencies, even when these contingencies are designed to elicit specific somatomotor responses (Gantt, 1960; Kazis, Milligan, \& Powell, 1973; Prokasy, 1984; Schneiderman, Smith, Smith, \& Gormezano, 1966). We have recently suggested that, under appropriate parametric circumstances, cardiac inhibition is an invariant conditioned response (CR) when rabbits, and perhaps other organisms as well, are exposed to signals that predict biologically significant events (Powell, Buchanan, \& Gibbs, 1990). For example, heart rate (HR) slowing is obtained in response to Pavlovian conditioned stimuli (CSs) under a wide variety of circumstances in rabbits, rats, cats, and humans (e.g., Bruner, 1969; Fitzgerald, Stainbrook, \& Francisco, 1985; Obrist et al., 1974; Prescott, Durkin, Furchtgott, \& Powell, 1992; see Powell et al., 1990, for a recent review).

However, with regard to these findings, there are two related issues that should be further explored. First, in some species (e.g., primates and dogs; Nathan \& Smith,

This research was supported by Department of Veterans Affairs Institutional Medical Research Funds and NSF Grant BNS 88-20379 to C.M.G. We thank Ann Dawson of Gold Leaf Productions for assistance with the illustrations and Elizabeth Hamel for preparation of the manuscript.
1971; Schoenfeld, Kadden, \& McMillan, 1974; Sutterer \& Obrist, 1972) and under some experimental arrangements (e.g., unrestrained, free-moving animals; Iwata \& LeDoux, 1988; Teyler, 1971), conditioned HR increases are obtained. Second, the biobehavioral significance of conditioned bradycardia, when it occurs, has been debated for some time (e.g., cf. Lacey \& Lacey, 1974, with Obrist et al., 1974). In a manner similar to that of Lacey and Lacey, we have suggested that cardiac inhibition is representative of a stimulus registration process that facilitates processing of sensory information for biological relevance, but that increases in somatomotor activity may mask inhibitory cardiac changes in tasks in which such activity is concomitantly elicited, resulting in conditioned HR increases (e.g., Powell et al., 1990).

Several of our previous experiments using rabbits support this conclusion (e.g., Powell \& Joseph, 1974; Powell \& Levine-Bryce, 1988). However, in all of our previous studies, an acoustic stimulus was employed as the CS, and paraorbital electric shock served as the unconditioned stimulus (US). To determine the extent to which bradycardia is indeed invariant during exposure to classical conditioning contingencies, other stimulus modalities must be examined under conditions that minimize concomitantly occurring increases in somatomotor activity. In the present experiments, we demonstrate that bradycardiac CRs develop in rabbits not only to acoustic CSs, but also 
to CSs consisting of changes in illumination and vibrotactile stimulation. In addition, we compare the conditioned bradycardia induced by Pavlovian contingencies involving either an aversive paraorbital electric shock or a moderately aversive, corneal airpuff as the US. In a final experiment, we show that signals that predict an appetitive US, consisting of an intraoral pulse of water to waterdeprived rabbits, also elicit conditioned bradycardia.

\section{GENERAL METHOD}

\begin{abstract}
Animals
The animals were experimentally naive, New Zealand albino or pigmented rabbits of both sexes, approximately 5 months of age at the beginning of the experiments. The animals were housed individually in an AAALAC-accredited animal facility, consisting of climate-controlled rooms with an 0700:1900-h light:dark cycle. All the experiments were conducted during the light portion of this cycle. Unless otherwise noted, ad-lib access to food and water was provided. During all phases of this research, the principles for the care and use of experimental animals, as outlined by the American Psychological Association and the U.S. Public Health Service, were strictly followed.
\end{abstract}

\begin{abstract}
Apparatus
During conditioning, the animals were restrained in standard Plexiglas rabbit restrainers (Gormezano, 1966) and placed in soundattenuating experimental chambers. The electrocardiogram (ECG) and eyeblink (EB) responses were recorded on a Grass Model 7 polygraph. ECG electrodes were made from stainless steel safety pins inserted beneath the skin on the right front leg and left haunch. Stainless steel eye clips were inserted beneath the upper and lower eyelids to serve as electrodes for measuring the corneoretinal potential (EB response) (Powell \& Levine-Bryce, 1988). EB signals were routed through a Grass Model 7 P-3 preamplifier, calibrated to give a 1-mm deflection of the oscillograph pen for each $100-\mu \mathrm{V}$ change in signal. The nictitating membrane (NM) response was recorded by a photoresistive transducer, as previously described by Gormezano and Gibbs (1988). The shock US was delivered by a TTL constant-current shock generator to stainless steel wound clips chronically applied $0.5 \mathrm{~cm}$ from the margins of the upper and lower eyelids. The corneal airpuff was produced from a source that was pressurized to 3.0 psi through copper tubing, mounted on an aluminum headpiece that also contained the NM transducer. All responses were recorded, and experimental events were controlled by a DEC Micro PDP 11 computer that was linked to the Grass polygraph and experimental chambers.
\end{abstract}

\section{Response Measurement}

EB and NM CRs were defined as $\geq 2$-mm deflections of the appropriate polygraph pen, corresponding to approximately $1-\mathrm{mm}$ response changes, during the CS period. Trials in which pre-CS EB or NM responses occurred and continued into the CS period were discarded during data analysis. However, less than $5 \%$ of the trials were discarded for this reason. Interbeat interval (IBI) durations derived from the ECG were assessed prior to and during CS presentation, to produce a beat-by-beat measure of HR change. This measure of cardiac change, which is referred to as heart period (HP), is the reciprocal of $\mathrm{HR}$, and was assessed by triggering the real-time clock of the computer by the R-wave of the ECG. Baseline HP in milliseconds was obtained by averaging the duration of IBIs occurring during the 4-sec period that immediately preceded CS onset. CS-evoked change in HP was obtained by subtracting this baseline value from the HP associated with each IBI occurring during the CS. During "test" trials, in which the US was not presented, baseline HP was subtracted from each of up to 10 consecutive post-CS IBIs to provide difference scores that were uncontaminated by the presentation of the US during, as well as following, CS presentation.

\section{Statistical Analysis}

In most cases, the HP data were analyzed by multifactor mixedeffects analyses of variance (ANOVAs), with repeated measures on post-CS periods and trials. EB CRs were subjected to a similar analysis, in which trials and sessions served as repeated measures. Frequency data were analyzed by the sign test. Where appropriate, post hoc tests were conducted using Tukey's procedure.

\section{EXPERIMENT 1}

Experiment 1 was designed to determine whether conditioned bradycardia occurred to CSs other than acoustic stimuli. Both changes in illumination and vibrotactile stimuli have been shown to be effective stimuli for classical conditioning of the NM response (e.g., see Gibbs, Kehoe, \& Gormezano, 1991; Schreurs, Jha, \& Gormezano, 1986). Although a prior experiment suggested that in some cases HR decelerations accompany EB conditioning in response to changes in illumination (Powell, Schneiderman, Elster, \& Jacobson, 1971), this study employed a relatively short CS/US or interstimulus interval (ISI), which is more optimal for EB than for HR conditioning (e.g., Kazis et al., 1973; Van Dercar \& Schneiderman, 1967). Also, because EB conditioning was of major interest, HR accelerations were often obtained, most likely due to the increases in somatomotor activity that accompanies EB conditioning (Powell \& Joseph, 1974). Consequently, in the present experiment, albino rabbits received aversive Pavlovian conditioning training, in which changes in illumination were employed as a CS, but in which an ISI of $4 \mathrm{sec}$, which is optimal for HR conditioning, was utilized. In addition, to further assess the generality of CS modality as a variable for eliciting conditioned bradycardia, other animals were subjected to conditioning training involving a vibrotactile CS, which consisted of $4 \mathrm{sec}$ of vibratory stimulation to the shaved back. Habituation of the HR orienting reflex (OR) was also assessed for each of these CS modalities.

\section{Method}

Two groups of 8 albino rabbits received classical conditioning training. One group was exposed to a 4,000-fc change in illumination as the CS, and a second group received a vibratory stimulus as the CS. The vibrotactile stimulus was produced by an ESCAP vibrator that had been removed from a silent pager. It was mounted directly on a $25 \times 50-\mathrm{mm}$ piece of sheet aluminum that was positioned tightly against the shaved back of the rabbit and held in place by surgical tape. The visual stimulus was produced by the activation of a $12-\mathrm{V} \mathrm{dc}$ incandescent pilot lamp, placed directly in front of the animal $20 \mathrm{~cm}$ from the front of the restrainer, and a $100-\mathrm{W}$, ac incandescent light bulb, which was located in the center of the chamber, approximately $25.0 \mathrm{~cm}$ above the animal's head. In both conditions, the US was a 3-mA, $60-\mathrm{Hz}$ ac paraorbital electric shock train. A single 50-trial session was employed, in which onset of a 4.25 -sec duration CS preceded the 250 -msec US by $4.0 \mathrm{sec}$ on each trial. The intertrial interval (ITI) varied pseudorandomly with an average of $60 \mathrm{sec}$ and a range of 30-90 sec. In each experiment, 
8 additional animals received 50 unpaired presentations each of the $\mathrm{CS}$ and US in a pseudorandom sequence, thus serving as nonassociative (i.e., pseudoconditioning) control groups. The ITI (whether CS or US trial) for the unpaired control groups was half that of the conditioning groups; the session duration was thus the same for all four groups. The animals were habituated to handling and restraint for a $1-\mathrm{h}$ period over 2 consecutive days prior to the beginning of the experiment. Then, on the day prior to conditioning or nonassociative training, 10 presentations of the CS alone were administered to compare habituation of the OR under these two stimulus conditions. Conditioning or nonassociative training began approximately $24 \mathrm{~h}$ later. In all other respects, the method was as described above (see General Method).

\section{Results}

The results of conditioning are shown in Figure 1, which indicates the change in HP from pre-CS baseline associated with the 10th IBI for both of the CS conditions

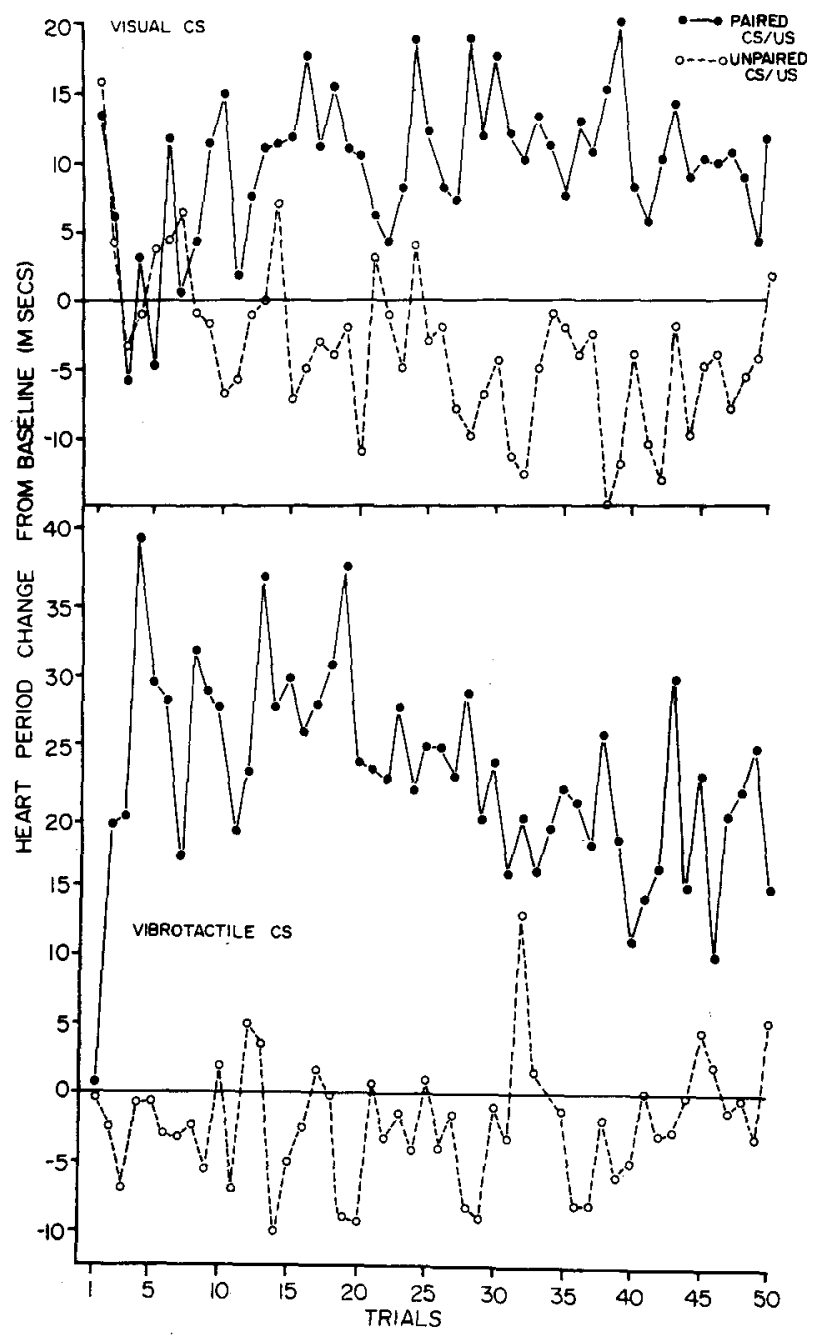

Figure 1. Change in heart period, from pre-CS baseline associated with the 10th interbeat interval following CS onset, of rabbits that received either a visual (top) or vibrotactile (bottom) CS paired with paraorbital electric shock as the US. Also shown are data from rabbits that received unpaired CS/US presentations. Data are plotted as a function of $\mathbf{5 0}$ sequential $\mathrm{CS}$ trials. and for both the paired and unpaired CS/US groups. The 10th IBI was chosen for presentation because it was the last IBI available for analysis in all the animals prior to CS offset; the IBI occurring at the end of the ISI is typically associated with the largest HR change from pre-CS baseline (Powell \& Levine-Bryce, 1988). However, the statistical analysis, as described below, was based on all post-CS IBIs. As illustrated in Figure 1, it is apparent that considerable conditioned bradycardia occurred to each of the CS modalities, as indicated by the differential increase in HP over trials in both conditioning groups compared with the pseudoconditioning control groups. The shape of the CR acquisition function was generally similar for each modality, although a difference can be seen during the early trials. Similar to acoustic CSs (see Powell \& Levine-Bryce), the visual CS produced a pronounced bradycardia at the beginning of training in both the conditioning and pseudoconditioning groups that decreased somewhat in magnitude over the first five to six trials. However, by Conditioning Trial 10, considerable bradycardia had reappeared in the conditioning group, although the response of the control group remained at near-zero levels. Unlike the visual CS, the response evoked by the vibratory CS did not show an initial decline. Instead, acquisition in this group appeared to begin during the first few trials, as indicated by the dramatic increase in CSevoked HP on Trials 2-4 in the conditioning group. On the other hand, little if any HP change occurred in the pseudoconditioning control group during this time.

One possible reason for these initial differences in acquisition for the two stimulus modalities can be seen by comparing habituation of the OR in the two groups of animals, as summarized in Figure 2. This figure shows HP change from prestimulus baseline, as a function of IBIs, for the first and last trial of OR assessment. Although the visual CS elicited a bradycardiac OR, which habituated over subsequent trials, the initial unconditioned HR response to the vibratory stimulus consisted of tachycardia for both the paired and unpaired groups. Thus, although ORs to light and tone stimuli are similar in direction to the CR, the cardiac OR to a vibratory stimulus is opposite in direction to the bradycardiac CR.

An ANOVA of the conditioning data for the visual stimulus conditions revealed significant group $[F(1,14)=$ $26.0, p<.0001]$ and group $\times$ trials $[F(49,680)=2.69$, $p<.001]$ effects. Similar significant effects were obtained for the vibrotactile conditions [group, $F(1,14)=$ 5.95, $p<.05$; group $\times$ trial, $F(49,680)=2.32, p<$ $.005]$. The post-CS IBI effect and IBI $\times$ group interaction (not shown in Figure 2) were also significant for both CS modalities (all $p \mathrm{~s}<.05$ ). Post hoc tests revealed that significant differences between the conditioning and pseudoconditioning groups occurred with the vibrotactile stimulus as early as Trial 2 . On the other hand, similar significant differences did not occur for the visual stimulus until Trials 9 and 10. Again, during habituation of the $\mathrm{OR}$, the poststimulus IBI effect and the trials effect were both significant (all $p \mathrm{~s}<.05$ ). 


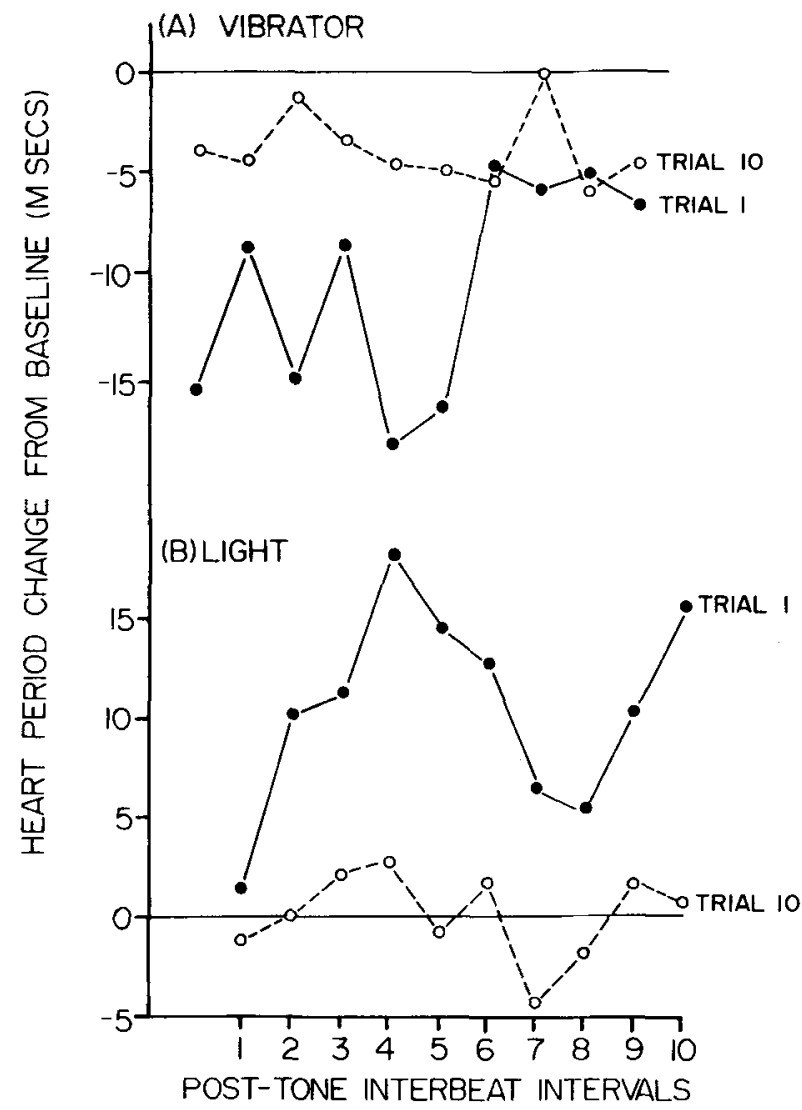

Figure 2. Heart period change from prestimulus baseline evoked during the 1st and 10th presentations of a vibrotactile $(A)$ and visual (B) stimulus prior to aversive conditioning training. Data are shown for 10 consecutive interbeat intervals following stimulus onset.

\section{Discussion}

These data suggest that bradycardiac CRs are induced by both visual and vibrotactile CSs. However, vibrotactile stimuli elicit tachycardiac ORs, whereas the OR elicited by both visual and acoustic (see Powell \& Levine-Bryce, 1988) stimuli consists of HR slowing. These differential findings with regard to elicitation of the $O R$ as a result of sensory modality give further credence to the conclusion that the initial pronounced bradycardia that is obtained on early paired CS/US trials, and its subsequent habituation with visual as well as acoustic stimuli (see Powell \& Levine-Bryce, 1988), actually represents elicitation and habituation of the cardiac OR. They also demonstrate that the HR CR to CSs, which precede an eyeshock US, consist of bradycardia, regardless of the modality of the CS.

Nevertheless, differences between the two modalities of stimulation were observed. For example, the rate of acquisition differed for the visual and vibrotactile groups; it was much faster in the group that received the vibrotactile stimulus as the CS. This dramatic increase in HP, from initial presentation of the stimulus on Trial 1 to greater than $20 \mathrm{msec}$ on Trial 2 and over $40 \mathrm{msec}$ on Trial 4, clearly represents an example of extremely rapid condi- tioning, as recently discussed at some length by Lennartz and Weinberger (1992). The overall magnitude of the CR was also somewhat greater for the vibrotactile than for the visual stimulus. In fact, the average $C R$ magnitude of around $15 \mathrm{msec}$ from pre-CS baseline for the visual CS is somewhat smaller than that typically obtained with acoustic CSs (e.g., see Powell \& Levine-Bryce, 1988). The relatively small-magnitude $\mathrm{CR}$ obtained with the visual CS may have been due to the use of albino rabbits as subjects, because visual acuity is relatively undeveloped in these animals. Hence, a visual stimulus would probably be a less salient CS than either tones or vibratory stimulation. The relatively greater and more rapid increase in CR magnitude obtained with the vibrotactile CS suggests that it is an even more salient $\mathrm{CS}$ than the 75-dB tones used in previous experiments (e.g., Powell \& Levine-Bryce). Thus, although these data suggest that conditioned bradycardia is obtained when each of these three kinds of sensory stimulation are employed as CSs, the magnitude and rate of acquisition of the CR under these three conditions is somewhat different.

\section{EXPERIMENT 2}

In Experiment 2, we examined the effects of utilizing a different US on the generality of conditioned bradycardia. In Experiment 1, paraorbital electric shock, which elicits robust EB unconditioned responses (URs), was utilized. Although many previous EB conditioning experiments have used a corneal airpuff as the US, the autonomic accompaniments of this relatively mild US have not been extensively studied. Consequently, in the next two experiments, an airpuff was utilized as the US.

\section{Method}

Sixteen New Zealand rabbits (8 albino and 8 pigmented) served as subjects. A 100-msec, 3-psi airpuff was employed as a US, and 4.1-sec, 75-dB SPL, 1216- or 304-Hz tones served as CSs in a differential conditioning paradigm. For half the animals, the $304-\mathrm{Hz}$ tone was $\mathrm{CS}+$ and the $1216-\mathrm{Hz}$ tone was $\mathrm{CS}-$; these conditions were reversed for the remaining animals. As in Experiment 1, CS + and US coterminated, resulting in a 4-sec ISI. Habituation to handling and restraint was carried out as in Experiment 1. Then, during each of three consecutive daily conditioning sessions, $25 \mathrm{CS}+$ and $25 \mathrm{CS}$ - trials were delivered in a pseudorandom order, with the airpuff invariably paired with the CS + but not with the CS- . Tone-evoked HP changes were assessed as described above.

\section{Results}

The results of Experiment 2 are illustrated in Figure 3, which shows HP change from pre-CS baseline of the 10th IBI following CS onset for CS + and CS - over the three consecutive sessions of training, plotted as a function of blocks of five trials each. Data from the albino and pigmented groups were combined, because an initial ANOVA revealed no significant group effects or interactions. Figure 3 shows that although HP increases occurred during the CS, these changes were relatively small compared with those obtained with the paraorbital shock in Experiment 1 . However, relatively greater HP in- 


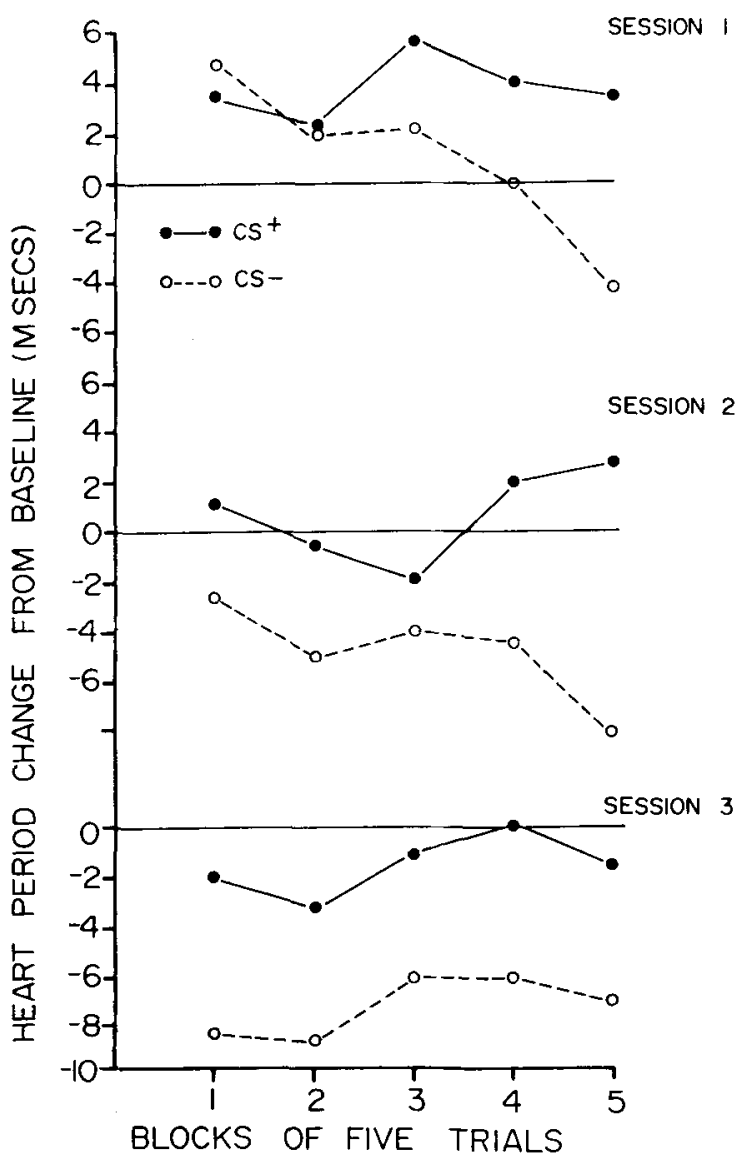

Figure 3. Change in heart period, from pre-CS baseline for the 10th interbeat interval, of rabbits that received 4-sec tones as CSs and a 100-msec airpuff as a US. The airpuff was systematically paired with either a 304- or 1216-Hz tone (CS+), whereas the other tone was unreinforced $(\mathrm{CS}-$ ). Twenty-five presentations of each tone occurred in a pseudorandom sequence during each of three consecutive sessions separated by approximately $24 \mathrm{~h}$.

creases occurred during the CS + than during the CS$[F(1,14)=7.02, p<.02]$. In fact, during Sessions 1 and 2 , relative $H P C R$ magnitude increased as a function of trials in response to the $\mathrm{CS}+$, whereas a concomitant decrease in response to the CS- occurred. Moreover, although the CR clearly consisted of HR slowing (increase in HP) in response to the CS + during each of the fivetrial blocks during Session 1, bradycardiac changes were observed only during the last two blocks of the second session and slight HP decreases (i.e. HR increases) were observed during Session 3. However, the response to the $\mathrm{CS}-$ consisted of even greater HR increases, which also resulted in a significant effect of sessions $[F(2,28)=6.5$, $p<.005]$. Posttests revealed significant CS differences on Trial Blocks 3, 4, and 5 during Session 1, on Trial Blocks 4 and 5 during Session 2, and for all the trial blocks during Session 3 (all $p s<.05$ ). Although not illustrated in Figure 3, the UR also consisted of HR increases.

\section{Discussion}

It is clear from the present experiment that an airpuff paired with a CS of relatively long duration elicits small but reliable conditioned cardiac responses. Initially, the direction of this response is identical to that obtained with the more aversive paraorbital shock (viz the CR is an HP increase), but with continued training, CR magnitude decreased; indeed, the HR CR actually became accelerative, as is the case with eyeshock USs (Powell \& Kazis, 1976). Nevertheless, it is clear that a signal that precedes a relatively nonaversive corneal airpuff, which is a potent US for classical EB conditioning, also elicits bradycardia as a CR.

\section{EXPERIMENT 3}

Although the airpuff was delivered to the cornea in Experiment 2, it is unlikely that concomitant EB and NM conditioning occurred, because the 4-sec ISI that was used does not support either EB or NM conditioning (Kazis et al., 1973; Schneiderman \& Gormezano, 1964): Relatively longer ISIs are required for optimal autonomic conditioning than for optimal EB or NM conditioning (e.g., see Kazis et al., 1973; Van Dercar \& Schneiderman, 1967). Nevertheless, small but reliable conditioned HR changes have been obtained with the relatively brief 0.5 sec ISI that is optimal for EB and NM conditioning (Powell \& Levine-Bryce, 1988). Thus, in the present experiment, HP CRs were assessed in response to a $0.6-\mathrm{sec}$ tone CS that was reinforced with the 100 -msec airpuff, which was identical to that used as the US in Experiment 2, to determine whether similar conditioned cardiac changes would accompany NM conditioning under these circumstances.

\section{Method}

After habituation to restraint, as described above, a single session, in which $10 \mathrm{CS}$-alone trials were presented, was employed to assess habituation of the HR OR. Four consecutive daily conditioning sessions followed, in which a $1216-\mathrm{Hz}, 600-\mathrm{msec}$ tone CS was consistently paired with a $100-\mathrm{msec}, 3-\mathrm{psi}$ airpuff. The airpuff overlapped the last $100 \mathrm{msec}$ of the tone, thus producing a 500 -msec ISI. Sixty trials were delivered during each session. IBI duration and NM occurrence during the 500-msec ISI was assessed on each trial. Trials 8 and 58 of each session served as nonreinforced "test" trials to permit assessment of the complete HP CR without contamination by US presentation. A nonassociative control group was also studied, in which 60 airpuffs and tones were presented per session in an explicitly unpaired fashion, as described in Experiment 1. Ten New Zealand albino rabbits served as experimental subjects in each group.

\section{Results and Discussion}

Tone-evoked NM and HP occurrence are presented in Figure 4. The top panel of this figure shows the percentages of conditioned NM CRs during each of the four conditioning sessions. The bottom panel illustrates the mean HP changes during the first and second IBIs following CS onset for each of the four conditioning sessions. As 
(A)

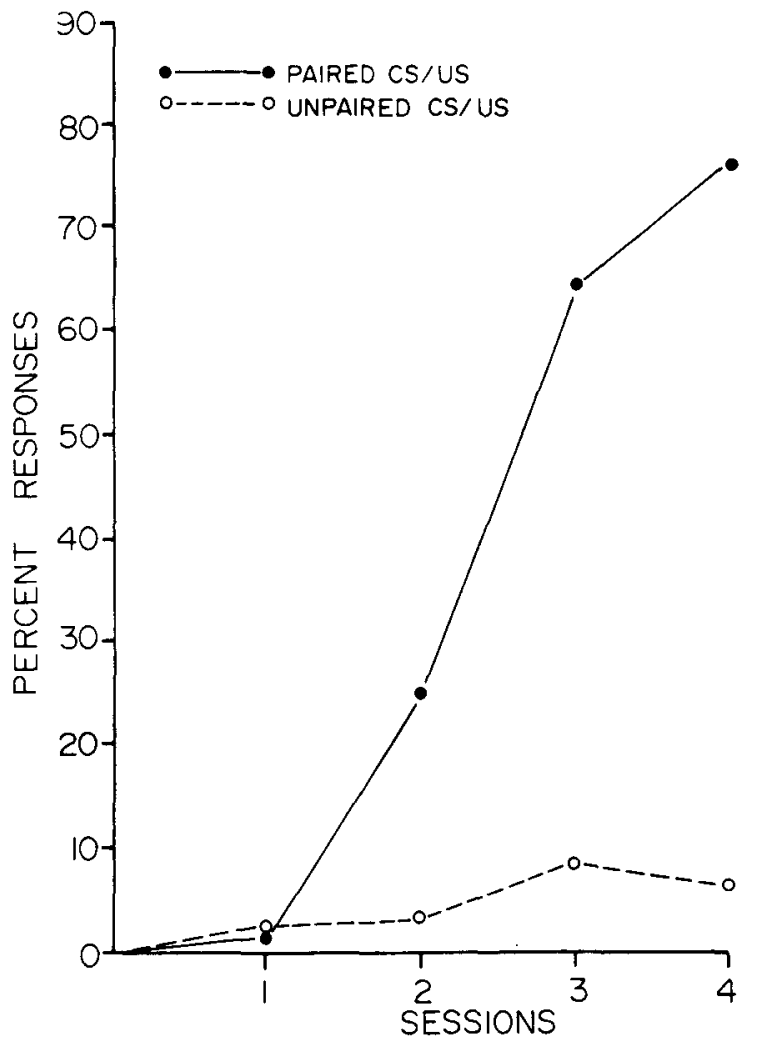

(B)

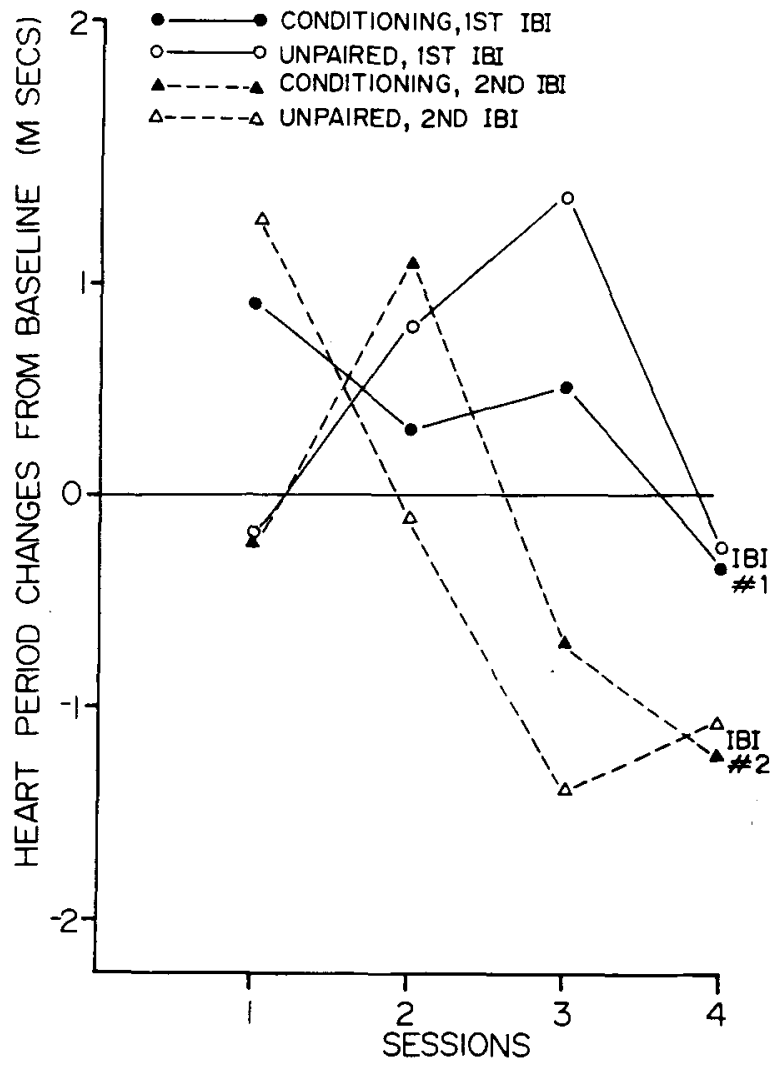

Figure 4. (A) Percentages of eyeblink conditioned responses in rabbits that received either pairings of a 600 -msec tone CS and a 100-msec airpuff US or explicitly unpaired CS and US presentations. Data are shown for four sessions, composed of 60 trials each. (B) Heart period change from pre-CS baseline associated with the first and second interbeat interval (IBI) following CS onset in rabbits that received classical eyeblink conditioning, as depicted in panel A. Data are shown separately for the paired (conditioning) and unpaired (pseuodoconditioning) groups.

can be seen from this figure, a typical acquisition function for the NM response occurred over the four sessions in the paired group, whereas relatively few NM CRs occurred in the control group. These data were not normally distributed, because most of the animals in the control group did not respond. However, all of the animals in the paired group met an acquisition criterion of 10 consecutive NM CRs, whereas none of the control animals did so-a difference that was significant by the sign test $(p<.01)$.

The HP OR (not shown) was similar to that previously described. Figure 4B suggests that little HP conditioning occurred. As can be seen, there were few differences between the conditioning and control groups. The response was somewhat more robust during the second IBI and during later sessions; however, differences between the paired and unpaired groups were not significant $(p>.10)$. Although the HP changes that occurred during the CS suggest that HR conditioning did not occur, evidence of HR conditioning was obtained on test trials. This finding is illustrated in Figure 5, which shows mean CS-evoked HP change plotted across the first $10 \mathrm{IBI}$ following CS onset for each session and test trial. As can be seen, the initial
HP response was considerably greater in the conditioning group than in the pseudoconditioning group. Although it declined somewhat from Trials 8 to 58 during all four sessions, the magnitude of the response appeared to be greater in the conditioning animals than in the pseudoconditioning animals during both of the test trials. This resulted in a significant group effect $[F(1,18)=4.39$, $p<.02]$ and a group $\times \mathrm{IBI}$ interaction $[F(1,10)=3.73$, $p<.05]$. These results suggest that although the magnitude of the HP change that occurs during a $0.5-\mathrm{sec}$ tone/ airpuff contingency is too small to be statistically reliable, due to the relatively short duration of the stimulus, when the CR is measured on nonreinforced "test" trials so that the full response is allowed to develop, relatively strong evidence of conditioning occurs. However, it should also be noted that the HR CR became smaller across sessions as NM conditioning developed.

\section{EXPERIMENT 4}

The results of the preceding experiments indicate that conditioned bradycardiac adjustments are induced by aversive Pavlovian training procedures involving a variety of 


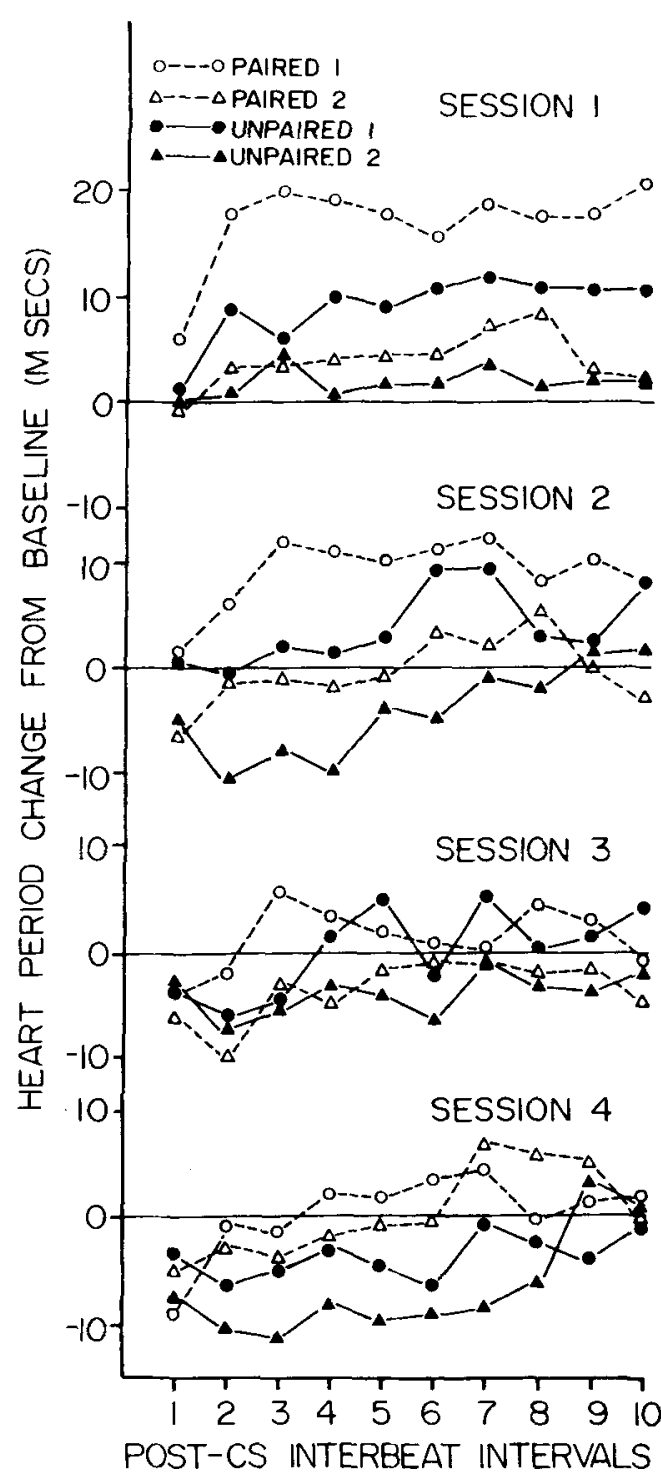

Figure 5. Mean CS-evoked change in heart period from pre-CS baseline associated with two test trials-Trials 8 (Test Trial 1) and 58 (Test Trial 2) -in which the CS was presented alone. Data are shown as a function of 10 consecutive interbeat intervals following CS onset, and are plotted separately for animals that received paired CS/US and explicitly unpaired presentations.

CS and US modalities. Experiment 4 was undertaken to determine whether appetitive Pavlovian conditioning training, involving repeated pairings of tone and water to rabbits with limited access to water, would also result in the development of bradycardiac CRs.

\section{Method}

Ten New Zealand albino rabbits were used as subjects. Approximately 2 weeks prior to behavioral training, a small ( $\sim 2 \mathrm{~mm}$ OD) polyethylene cannula was implanted in the right cheek of each animal under general anesthesia and aseptic conditions, according to protocols detailed elsewhere (Gibbs, 1992; Smith, DiLollo, \& Gormezano, 1966). Five to 7 days later, each animal was placed on a maintenance regimen that limited daily access to water to a sin- gle, fixed, 1-h period. On Day 8 of this regimen, the animals were adapted to handling and restraint, and on the following day a single session of differential appetitive conditioning training was accomplished. This training involved the two distinctive, tone CSs (304 and $1216 \mathrm{~Hz}$ ) described in Experiment 2. CS duration was $1 \mathrm{sec}$, and the intensity of each tone was $75 \mathrm{~dB}$ SPL. One tone $(\mathrm{CS}+)$ was paired with a $1-\mathrm{sec}, 1-\mathrm{ml}$ intraoral pulse of water delivered through the previously implanted cheek cannula; tone offset and water onset were contiguous. The second $(\mathrm{CS}-)$ tone was presented alone. Training consisted of $30 \mathrm{CS}+$ and $30 \mathrm{CS}-$ trials, delivered in a pseudorandom sequence at intervals of 45-75 sec ( $M=60 \mathrm{sec}$ ). For assessment of training effects on HR, the water US was omitted on the 10 th, 20th, and 30th presentations of the $\mathrm{CS}+$; on these "test" trials, as well as on the numerically corresponding CS - trials, HP measures were obtained during the 4-sec period immediately preceding and during each of four consecutive 1 -sec periods following tone onset. In addition, jaw movements (JMs) associated with swallowing were recorded on test trials, as previously described (Gormezano \& Gibbs, 1988; Smith et al., 1966).

\section{Results}

Figure 6 summarizes the effects of differential appetitive conditioning training on tone-evoked changes in HP. As illustrated in the upper panel of this figure, and similar to the results of Experiment 2, differential appetitive
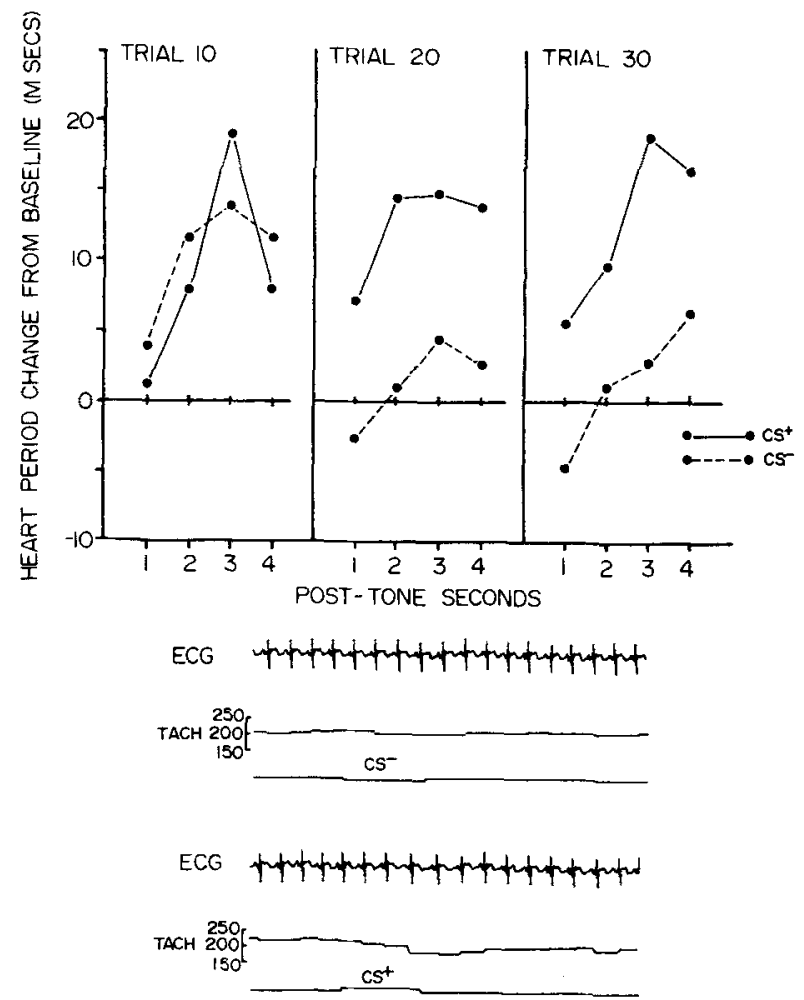

Figure 6. Top: Mean heart period change, from pre-CS baseline during three nonreinforced test trials, of rabbits that received 1-sec, 304- or 1216-Hz tones as CSs and a 1-ml pulse of water as a US. The US was systematically paired with the CS+ but never with the CS - . Data are shown as a function of four post-CS seconds. Bottom: Polygraph tracing of typical cardiac response to the appetitive $\mathbf{C S}+$ and $\mathbf{C S}-$. ECG = electrocardiogram; $\mathbf{T A C H}=$ tachometric equivalents of heart rate in beats per minute. 
conditioning rapidly induced discriminative, tone-evoked bradycardia. Although similar HP responses occurred on the initial CS + and CS - test trials, later test presentations of the CS + elicited markedly greater increases in $\mathrm{HP}$ than did those of the CS - (mean HP changes $=12.4$ vs. $1.3 \mathrm{msec}$ ). An example of the evoked HR slowing in response to CS + and CS - is illustrated in the bottom panel of Figure 6. An ANOVA applied to these data confirmed that these findings were reliable. Significant effects of $C S[F(1,9)=11.43, p<.01]$ and $C S \times$ trials $[F(2,17)=3.70, p<.05]$ were obtained. Planned, twotailed $t$ tests indicated that the overall evoked changes in HP on the second and third CS + test trials (i.e., Trials 20 and 30 ) were significantly greater than those on the corresponding CS - trials $[t(9)=3.29$ and 3.39 , respectively, $p s<.01]$.

Tone-evoked JM CRs also occurred. With a response window of 0.1-4.0 sec following tone onset, JM CRs occurred on $44 \%$ of the trials. JM CR occurrence was similar to CS + and CS - on the first two test trials, but discriminative responding to the $\mathrm{CS}+$ versus $\mathrm{CS}-$ occurred by the end of training on Test Trial 3 . Consistent with these group differences, an ANOVA revealed a significant CS $\times$ trial interaction $[F(2,15)=4.21, p<$ .04 ], which was attributable to the greater number of responses to the third test presentation of the CS + versus CS $-[t(9)=3.19, p<.02]$.

\section{GENERAL DISCUSSION}

Taken together, the results of the present experiments strongly suggest that one of the components of the anticipatory response to the signal stimuli during classical conditioning is cardiac inhibition under a wide variety of circumstances. Both visual and vibrotactile stimuli elicited conditioned bradycardia when repeatedly paired with aversive paraorbital electric shock as the US, and it has been demonstrated in many previous experiments that acoustic CSs paired with paraorbital shock also elicit CS-evoked bradycardia (Powell \& Levin-Bryce, 1988; Schneiderman et al., 1966). Thus, the anticipatory cardiac changes elicited by Pavlovian CSs, regardless of sensory modality, appear to be inhibitory.

However, there are subtle differences between the cardiac CRs evoked by these CSs, at least when applied to the rabbit. For example, in the present studies, the vibrotactile CS evoked a CR of considerably larger magnitude than did the visual CSs; the cardiac component of the OR was also opposite for these two kinds of stimuli. The OR elicited by the visual CS was a decrease in HR, similar to that evoked by acoustic stimuli, but HR increases characterized the OR that was elicited by vibrotactile stimuli. This difference may be related to the extremely rapid conditioning observed in the latter animals compared with the animals that received visual CSs, based on the present data, or auditory CSs, based on previous reports (e.g., Powell et al., 1990). In the latter two situations, there is an initial decline in CR magnitude followed by a subsequent increase in response amplitude, representing $C R$ acquisition. The animals exposed to vibrotactile CSs, however, showed immediate CR acquisition. In fact, HP increases in this group were greater than those of an unpaired CS/US control group on the second trial of training. However, this may have occurred because, for rabbits, the vibrotactile stimulus is more salient than visual or auditory stimuli. In any case, it should be stressed that these differences are relatively minor when it is considered that all CSs studied thus far evoke rather robust decelerative HR changes (see Powell et al., 1990).

It is also notable that different kinds of USs elicit conditioned bradycardia under appropriate parametric circumstances. Thus, an airpuff US, which has been utilized in numerous prior experiments to elicit classically conditioned EB and NM CRs, also resulted in CS-evoked cardiac decelerations. Although the cardiac changes in the latter instance were relatively small compared with those elicited by the more aversive paraorbital shock, differential bradycardiac CRs occurred in both pigmented and albino rabbits. The relatively small $\mathrm{HP}$ changes obtained under these conditions were most probably due to the relatively low intensity of the airpuff.

McEchron, McCabe, Green, Llabre, and Schneiderman (1991) recently showed that cardiac decelerations of a magnitude comparable to that obtained with paraorbital shock can be elicited by relatively intense airpuff USs that also elicit tachycardiac URs, as did the airpuff UR in the present study. These investigators examined three US intensities $\left(2.2,18.3\right.$, and $\left.5.9 \mathrm{~N} / \mathrm{cm}^{2}\right)$; the lowest intensity employed was comparable to the 3-psi intensity employed in the present study. Although McEchron et al. found that CS-evoked bradycardia occurred with this US intensity, it was not as great as that shown in response to the highest intensity US employed and, moreover, was not significantly greater than that shown by a nonassociative control group that received explicitly unpaired presentations of the highest intensity airpuff and the tone CS. The latter animals also showed tone-evoked bradycardia; however, this group would not appear to be an adequate control group for conditioning animals that received the low intensity US, because their unpaired training was solely with the high-intensity US. A number of other differences between the present experiments and that of McEchron et al. make comparisons between the two studies difficult. Nevertheless, it is important to note that in spite of these differences, the conclusion of both studies is that conditioned bradycardia is supported by airpuff USs under appropriate parametric circumstances.

It is also noteworthy that an appetitive US involving water administered to water-deprived animals elicits CSevoked bradycardia. Like other USs studied (i.e., eyeshocks and airpuffs), the UR consists of tachycardia. The use of water as a US in rabbits has been studied extensively by Gormezano and associates as an appetitive model of classical somatomotor conditioning (Gibbs, 1992; Gor- 
mezano, 1972; Gormezano, Kehoe, \& Marshall, 1983; Smith, DiLollo, \& Gormezano, 1966). As was found in the present experiments, a sinusoidal movement of the jaw muscles as an anticipatory masticatory response during the CS is usually obtained as the somatomotor CR. It has been demonstrated through the use of both an instrumental runway and an operant licking paradigm (Gormezano, 1980; Schwartzbaum, 1983) that the presentation of water to water-deprived animals in this manner is indeed an appetitive stimulus, because the animals will also exhibit operant responses to ensure its delivery. It should be noted, however, that the CS/US parameters utilized in the present appetitive conditioning experiment are not optimal for acquisition of the Pavlovian JM CR. A 4-sec ISI induces more rapid acquisition of robust JM CRs than the $1-\mathrm{sec}$ interval used here, a finding that is not confounded by elevated levels of "pseudoconditioned" responding (Gibbs, 1992; Gibbs, Kirkpatrick-Steger, Watson, Gibbs, \& Gormezano, 1993). However, when the 4-sec ISI is used, conditioned cardiac accelerations, rather than decelerations, are usually obtained (Gibbs et al., 1992). The rapid acquisition of the JM CR under these circumstances results in rapid increases in somatomotor activity and, quite likely, increased demands on cardiovascular output that would mask any concurrent, anticipatory increases in vagal tone. The lack of robust, early-occurring JM CRs in Experiment 4, in which a 1-sec ISI was employed, thus did not allow for interference with the normally occurring anticipatory cardiac decelerations by increases in somatomotor activity.

It is well known that learned cardiac increases occur when the skeletal $\mathrm{CR}$ involves increases in somatomotor activity (Obrist et al., 1974). This should not, however, detract from the equally important finding that anticipatory cardiac decreases are associated with a wide range of different CSs paired with either appetitive or aversive USs under appropriate parametric circumstances during classical conditioning. The optimal stimulus parameters for eliciting cardiac conditioning using aversive conditioning contingencies are also not optimal for elicitation of the EB or NM CRs. Indeed, the 400-500-msec ISI, which is optimal for eliciting NM and EB CRs, yields little evidence of HR conditioning, unless test trials are employed (see Experiment 3), although small but reliable CS-evoked bradycardia can be obtained under appropriate circumstances (Powell \& Levine-Bryce, 1988). However, the HR CR develops an accelerative component under these circumstances that only becomes apparent when the EB CR reaches asymptote (Powell \& Kazis, 1976; Powell \& Levine-Bryce, 1988). Thus, both appetitive and aversive conditioning paradigms are accompanied by HR increases when parameters are appropriate for eliciting concomitant somatomotor CRs. However, the present experiments clearly show that when such somatomotor demands on the circulation are lacking, CS-evoked cardiac inhibition is obtained. In this context, it is important to note that species that have been reported to show accelerative HR
CRs (e.g., dogs and nonhuman primates) also show conditioned increases in somatomotor activity (Nathan \& Smith, 1971; Obrist et al., 1974).

However, under conditions in which movement is minimized, both aversive and appetitive USs result in cardiac inhibition when paired with initially "neutral" CSs of various modalities. This is an especially important generalization in the context of characterizing the kinds of behaviors that these autonomic changes might represent. For example, the aversive classical conditioning paradigm has often been couched in terms of "fear" conditioning (Kapp, Frysinger, Gallagher, \& Haselton, 1979; LeDoux, Iwata, Cicchetti, \& Reis, 1988). It is clear, however, that cardiac inhibition is not always indicative of "fear," because an appetitive stimulus also elicits these changes. Some other characterization of this learned autonomic change is thus necessary. We have suggested that earlyoccurring, classically conditioned autonomic changes are associated with the "acquisition of facts" regarding one's environment (Powell \& Levine-Bryce, 1988), a type of learning that has previously been characterized as "declarative" (Anderson, 1983; Squire, 1992). Autonomic changes that accompany such learning may then reflect the affective component of this learned response, whether positive or negative. On the other hand, the much later acquisition of the classically conditioned EB, NM, and other somatomotor (e.g., JM) responses represents the acquisition of a skeletal behavior designed to deal adaptively with environmental contingencies. Such behaviors appear to reflect a "procedural" form of learning (Powell \& Levine-Bryce) that is compatible with the acquisition of procedures during human information processing, as described by Anderson (1983), Squire (1992), and others. Although there are, obviously, other ways of classifying these two types of learning, the simple statement that autonomic CRs represent "emotional" learning leaves a great deal to be desired as an explanatory construct.

As recently discussed by Lennartz and Weinberger (1992), at the very least, the occurrence of a set of rapidly acquired nonspecific autonomic responses and a separate set of more slowly acquired specific somatomotor (e.g., EB and NM) responses provides strong support for a twofactor hierarchical model of associative learning. These findings are also compatible with the recent suggestion by Thompson (1991) that two kinds of neural substrates support associative learning. The first, centered on the hippocampus and other interconnected limbic structures, was referred to as a "distributed" substrate. It was suggested that this substrate supports a general factor that is not necessary for simple classical conditioning of skeletal responses, but modulates associative learning in a variety of ways. The second, centered on extrapyramidal structures (e.g., the cerebellar cortex and its related deep nuclei), was referred to as a set of "localized" substrates that individually support specific learned somatomotor responses. A wide array of data suggest that the distributed structures described by Thompson (1991) mediate autonomic 
conditioning (e.g., Kapp et al., 1979; LeDoux et al., 1988; Powell et al., 1990; Schneiderman et al., 1987).

The ecological significance of the occurrence of inhibitory cardiovascular CRs has been debated at length (e.g., cf. Lacey \& Lacey, 1974 with Elliot, 1974). We believe that its widespread generality suggests that it is not an epiphenomenon associated with the inhibition of somatomotor activity, as some have suggested (e.g., Obrist et al., 1974). Instead, we feel that its adaptive significance is probably related to "attention-like" phenomena, as Lacey and Lacey have suggested. The interference with classically conditioned somatomotor behaviors by peripheral autonomic blockade supports this position (e.g., Albiniak \& Powell, 1980). Also compatible with this conclusion is the finding that a major central nervous system substrate that appears to participate in the acquisition of classically conditioned bradycardia in the rabbit prominently involves the anterior cingulate and midline prefrontal cortex, which have been shown in a variety of contexts to be associated with attention (e.g., Posner, Petersen, Fox, \& Raichle, 1988; Powell et al., 1990).

\section{REFERENCES}

Albiniak, B. A., \& Powell, D. A. (1980). Peripheral autonomic mechanisms and Pavlovian conditioning in the rabbit (Oryctolagus cuniculus). Journal of Comparative \& Physiological Psychology, 94, 1101-1113.

ANDERSON, J. R. (1983). The architecture of cognition. Cambridge, MA: Harvard University Press.

Bruner, A. (1969). Reinforcement strength in classical conditioning of leg flexion, freezing and heart rate in cats. Conditional Reflex, 4 , 24-31.

Elliot, R. (1974). The motivational significance of heart rate. In P. A. Obrist, A. H. Black, J. Brener, \& L. V. Dicara (Eds.), Cardiovascular psychophysiology: Current issues in response mechanisms, biofeedback and methodology (pp. 505-537). Chicago: Aldine.

Fitzgerald, R. D., Stainbrook, G., \& Francisco, D. (1985). Classically conditioned bradycardia and skeletal-motor activity in restrained rats. Physiological Psychology, 13, 211-216.

GANTT, W. H. (1960). Cardiovascular component of the conditional reflex to pain, food, and other stimuli. Physiological Review, 40, 266-291.

GibBs, C. M. (1992). Divergent effects of deep cerebellar lesions on two different conditioned somatomotor responses in rabbits. Brain Research, 585, 395-399.

Gibas, C. M., Kehoe, E. J., \& Gormezano, I. (1991). Conditioning of the rabbit's nictitating membrane response to a CSA-CSB-US serial compound: Manipulations of CSB's associative character. Journal of Experimental Psychology: Animal Behavioral Processes, 17, 423-432.

Gibbs, C. M., KirkPatrick-Steger, K., Watson, K. L., Gibbs, A. W., \& GoRmEZANO, I. (1993). Lesions of the amygdaloid central nucleus and substantia innominata disrupt appetitive Pavlovian conditioning in rabbits. Manuscript submitted for publication.

Gormezano, I. (1966). Classical conditioning. In J. B. Sidowski (Ed.), Experimental methods of instrumentation in psychology (pp. 385-420). New York: McGraw-Hill.

GORMEZANO, I. (1972). Investigations of defense and reward conditioning in the rabbit. In A. H. Black \& W. F. Prokasy (Eds.), Classical conditioning II: Current research and theory (pp. 151-181). New York: Appleton-Century-Crofts.

Gormezano, I. (1980). Pavlovian mechanisms of goal-directed behavior. In R. F. Thompson, L. H. Hicks, \& V. B. Shvyrkov (Eds.), Neural mechanisms of goal-directed behavior and learning (pp. 39-56). New York: Academic Press.
Gormezano, I., \& GibBs, C. M. (1988). Transduction of the rabbit's nictitating membrane response. Behavior Research Methods, Instruments, \& Computers, 20, 18-21.

Gormezano, I., Kehoe, E. J., \& Marshall, B. S. (1983). Twenty years of classical conditioning research with the rabbit. Progress in Psychobiology and Physiological Psychology, 10, 197-275.

IWATA, J., \& LeDoux, J. E. (1988). Dissociation of associative and nonassociative concomitants of classical fear conditioning in the freely behaving rat. Behavioral Neuroscience, 102, 66-76.

Kapp, B. S., Frysinger, R. C., Gallagher, M., \& Haselton, J. R. (1979). Amygdala central nucleus lesions: Effect on heart rate conditioning in the rabbit. Physiology \& Behavior, 23, 1109-1117.

Kazis, E., Milligan, W. L., \& Powell, D. A. (1973). Autonomicsomatic relationships: Blockade of heart rate and comeoretinal potential. Journal of Comparative \& Physiological Psychology, 84, 98-110.

LACEY, B. C., \& LACEY, J. I. (1974). Studies of heart rate and other bodily processes in sensorimotor behavior. In P. A. Obrist, A. H. Black, J. Brener, \& L. V. DiCara (Eds.), Cardiovascular psychophysiology: Current issues in response mechanisms, biofeedback, and methodology (pp. 538-564). Chicago: Aldine.

LeDoux, J. E., Iwata, J., Cicchetti, P., \& Reis, D. J. (1988). Different projections of the central amygdaloid nucleus mediate autonomic and behavioral correlates of conditioned fear. Journal of Neuroscience, 8, 2517-2529.

Lennartz, R. C., \& Weinberger, N. M. (1992). Analysis of response systems in Pavlovian conditioning reveals rapidly versus slowly acquired conditioned responses: support for two factors, implications for behavior and neurobiology. Psychobiology, 20, 93-119.

McEchron, M. D., McCabe, P. M., Green, E. J., Llabre, M. M., \& SChNeiderman, N. (1991). Air puff versus shock unconditioned stimuli in rabbit heart rate conditioning. Physiology \& Behavior, 51, 195-199.

Nathan, M. A., \& Smith, O. A. (1971). Conditional cardiac and suppression responses after lesions in the dorsomedial thalamus of monkeys. Joumal of Comparative \& Physiological Psychology, 76, 66-73.

Obrist, P. A., Howard, J. L., Lawler, J. E., Galosy, R. A., Meyers, K. A., \& Gabbelein, C. J. (1974). The cardiac-somatic interaction. In P. A. Obrist, A. H. Black, J. Brener, \& L. V. DiCara (Eds.), Cardiovascular psychophysiology (pp. 136-162). Chicago: Aldine.

Posner, M. I., Petersen, S. E., Fox, P. T., \& Raichle, M. E. (1988). Localization of cognitive operations in the human brain. Science, 240, 1627-1631.

Powell, D. A., Buchanan, S. L., \& GibBs, C. M. (1990). Role of the prefrontal-thalamic axis in classical conditioning. In H. B. M. Uylings, C. G. Van Eden, J. P. C. De Bruin, M. A. Corner, \& M. G. P. Feenstra (Eds.), Progress in brain research: Vol. 85. The prefrontal cortex: Its structure, function and pathology (pp. 433-466). Amsterdam: Elsevier.

Powell, D. A., \& JoSEPH, J. A. (1974). Autonomic-somatic interaction and hippocampal theta activity. Journal of Comparative \& Physiological Psychology, 87, 978-986.

Powell, D. A., \& KAzIS, E. (1976). Blood pressure and heart rate changes accompanying classical eyeblink conditioning in the rabbit (Oryctolagus cuniculus). Psychophysiology, 13, 441-447.

Powell, D. A., \& Levine-Bryce, D. (1988). A comparison of two model systems of associative learning: Heart rate and eyeblink conditioning in the rabbit. Psychophysiology, 25, 672-682.

Powell, D. A., Schneiderman, N., Elster, A. J., \& Jacobson, A. (1971). Differential classical conditioning in rabbits (Oryctolagus cuniculus) to tones and change in illumination. Journal of Comparative \& Physiological Psychology, 76, 267-274.

Prescott, L., Durkin, M., Furchtgott, E., \& Powell, D. A (1992). Concomitant heart rate and eyeblink Pavlovian conditioning in human subjects as a function of interstimulus interval. Psychophysiology, 29, 646-656.

Prokasy, W. F. (1984). Acquisition of skeletal conditioned responses in Pavlovian conditioning. Psychophysiology, 21, 1-13.

Schneiderman, N., \& Gormezano, I. (1964). Conditioning of the nictitating membrane of the rabbit as a function of CS-US interval. Journal of Comparative \& Physiological Psychology, 57, 188-195. 
SChneiderman, N., McCabe, P. M., Haselton, J. R., Ellenberger, H. H., Jarrell, T. W., \& Gentile, C. G. (1987). Neurobiological bases of conditioned bradycardia in rabbits. In I. Gormezano, W. F. Prokasy, \& R. F. Thompson (Eds.), Classical conditioning III (pp. 3763). Hillsdale, NJ: Eribaum.

Schneiderman, N., Smith, M. C., Smith, A. C., \& Gormezano, I. (1966). Heart rate classical conditioning in rabbits. Psychonomic Science, 6, 241-242.

Schoenfeld, W. N., Kadden, R. M., \& McMillan, J. C. (1974). Cardiac conditioning and extinction in Macaca mulatta during block of the CR by cardiac pacing. Pavlovian Journal of Biological Science, 9, 1-16.

Schreurs, B. G., JHA, B., \& Gormezano, I. (1986). Classical conditioning of the rabbit's nictitating membrane response to a piezoceramic vibrotactile CS. Behavior Research Methods, Instruments, \& Computers, 18, 359-362.

SchWARTZBaum, J. S. (1983). Operant licking in rabbits for intraoral injection of basic types of tastants. Physiology \& Behavior, 31, 445-451.

Smith, M. C., Dilollo, V., \& Gormezano, I. (1966), Conditioned jaw movement in the rabbit. Journal of Comparative \& Physiological Psychology, 62, 479-483.
SQuire, L. R. (1992). Memory and the hippocampus: A synthesis from findings with rats, monkeys, and humans. Psychological Review, 99, 195-231.

Sutterer, J. R., \& Orrist, P. A. (1972). Heart rate and general activity alterations of dogs during several aversive conditioning procedures. Joumal of Comparative \& Physiological Psychology, 80, 314-326.

TEYLER, T. J. (1971). Effects of restraint on heart-rate conditioning in rats as a function of US location. Journal of Comparative \& Physiological Psychology, 77, 31-37.

Thompson, R. F. (1991). Are memory traces localized or distributed? Neuropsychologia, 29, 571-582.

VAN DeRCAR, D. H., \& SChNeiderman, N. (1967). Interstimulus interval functions in different response systems during classical discrimination conditioning of rabbits. Psychonomic Science, 9, 9-10.

(Manuscript received July 11, 1992;

revision accepted for publication February 25, 1993.) 